\title{
Concepções, crenças e hábitos de consumo de uma comunidade escolar relativamente aos produtos light
}

\section{Resumo}

Apesar da importância que a Educação Alimentar tem no momento actual, ainda é grande a desinformação e o desconhecimento sobre a influência da alimentação na saúde cardiovascular. Sabendo que a escola deve ser um local fomentador de um estilo de vida saudável, o objectivo deste estudo é caracterizar os conhecimentos e comportamentos relacionados com os produtos light de alunos de uma Escola Pro- motora de Saúde que terminam a escolaridade básica e das pessoas que têm a responsabilidade de os formar nesta área. Os dados, recolhidos junto de alunos, professores, encarregados de educação e responsável pelos bares e refeitório, indicam que os participantes no estudo têm um conhecimento limitado destes produtos, associado a comportamentos pouco fundamentados.

\section{Introdução}

A necessidade da Educação para a Saúde torna-se cada vez mais premente, à medida que os cidadãos compreendem que os problemas de saúde e de doença estão associados ao estilo de vida e ao comportamento. Estes são os principais responsáveis pelo bem-estar individual e pela qualidade de vida das populações. Por isso, actualmente, a saúde dos indivíduos depende essencialmente da adopção de comportamentos saudáveis (Coucello, 1997).

É urgente e necessário encorajar a adopção de um estilo de vida saudável o mais cedo possível, devendo esse estilo ser iniciado na escola, através da educação e da prevenção (por meio de acções pontuais contextualizadas e/ou por intermédio do currículo). Pese embora o facto de esta ser uma responsabilidade de todas as escolas, as Escolas Promotoras de Saúde devem estar especialmente motivadas para esta acção.

Hoje em dia é cada vez mais comum encontrar produtos diet ou light nas prate- leiras de supermercados. Uma volta no supermercado é o suficiente para se encontrar dezenas de produtos com estas características, desde bebidas até lacticínios, passando por doces e biscoitos. Na busca de novos e saudáveis hábitos alimentares, estes produtos com menos calorias e gorduras, são apresentados pela publicidade, aos consumidores, como produtos mais saudáveis.

Assim, os objectivos deste estudo são:

- Identificar as concepções e as crenças dos diferentes intervenientes em uma comunidade escolar (alunos, professores, encarregados de educação e responsáveis) acerca de alguns produtos que interferem com o coração, nomeadamente os produtos light;

- Caracterizar as práticas dos intervenientes relativamente ao consumo desses produtos;

- Identificar as origens/causas da inclusão desses produtos nos hábitos alimentares dos membros dessa comunidade escolar.

\section{1 Os produtos light e diet e a educação para a saúde}

O uso dos produtos light de forma correcta requer uma clarificação do respectivo conceito que permita distingui-los dos produtos diet e melhor conhecimento das suas características e influências na saúde.

Nos alimentos industrializados, o termo light é usado para designar uma redução de, pelo menos, 25\% de calorias, gorduras, hidratos de carbono ou proteínas, isto é, há uma diminuição de um ou mais dos componentes calóricos e não a sua eliminação total do alimento. Essa redução deve estar claramente descrita na embalagem. A ingestão de produto light é uma opção leve, menos calórica, direccionada para os consumidores que desejem uma alimentação mais saudável, e que não necessitem de fazer um regime alimentar específico (Pereira, 2000).

A palavra diet, quando presente na embalagem dos alimentos, significa que aquele alimento apresenta exclusão total de um determinado componente para

\footnotetext{
* Professora da Escola Secundária/3. ${ }^{\circ}$ Ciclo Tomaz de Figueiredo, Rua Dr. Joaquim Carlos da Cunha Cerqueira, Apartado 109, 4974 -951 Arcos de Valdevez, Portugal, rcodeco@portugalmail.pt
} 
atender a necessidades metabólicas específicas (por exemplo, ela pode significar ausência de açúcar, glúten, sal, etc.), embora isso não signifique que ocorra sempre uma redução de calorias. De facto, os componentes excluídos são geralmente substituídos por outros para manter o gosto ou a característica do produto, podendo os novos componentes ser tão ou mais calóricos que os antigos. A título de exemplo, refira-se que em chocolates diet o açúcar é substituído por adoçantes, o que modifica a sua consistência, pelo que, para manter a textura habitual do chocolate, aumenta-se a gordura na sua composição, o que os deixa com valores calóricos equivalentes. Desta forma, a ingestão de produtos diet é apenas útil para pessoas que não podem ingerir um determinado tipo de alimento: um diabético necessitará de produtos diet com ausência de açúcar, um hipertenso de alimentos com ausência de sal, etc. (Monteiro, 2001).

Em relação aos produtos light, o seu consumo também não deve ser feito de forma indiscriminada. Sendo menos calóricos, estes produtos só ajudarão a melhorar a alimentação dos seus consumidores, desde que a soma de calorias dos alimentos light consumidos seja menor que a dos alimentos normais, ou seja, evitando-se o erro de aumentar a quantidade de produtos light consumidos relativamente aos mesmos produtos normais (Nan, 1999). Em síntese, os produtos light poderão contribuir para uma alimentação saudável, desde que o seu consumo obedeça a critérios nutricionais claros.

A legislação portuguesa é omissa na definição dos valores-limite para que determinado produto se apresente como light ou diet, apenas definindo o teor máximo de gordura para diferenciar produtos magros, meio-gordos e gordos, como é o caso dos leites, margarinas, iogurtes e queijos. No entanto, há uma nova proposta da Comissão Europeia no sentido de estabelecer os valores máximos e mínimos para que um produto se apresente como light ou diet, a ser aprovada brevemente, cabendo depois aos Estados membros adaptar-se a ela até 2006, no sentido de melhorar a informação e a saúde do consumidor. Até ao presente, a Organização Mundial de Saúde e a comunidade científica parecem não se ter debruçado sobre a influência na saúde deste tipo de produtos (WHO, 2002).

\section{Metodologia}

Este estudo incidiu na comunidade escolar da Escola Secundária com 3. ${ }^{\circ}$ Ciclo do Ensino Básico Tomaz de Figueiredo em Arcos de Valdevez, por ser uma Escola Promotora de Saúde e a escola onde trabalha a autora da investigação.

Para a sua concretização, utilizou-se uma amostra constituída por quatro subgrupos: alunos $\left(n_{A}=113\right)$, pertencentes às cinco turmas do $9 .^{\circ}$ ano de escolaridade existentes na Escola, no ano lectivo 2001/02, a totalidade dos seus professores $\left(n_{p}=26\right)$, a totalidade dos encarregados de educação $\left(n_{E}=31\right)$ e o membro do Conselho Executivo responsável pela gestão dos espaços escolares bares e refeitório $\left(\mathrm{n}_{\mathrm{CE}}=1\right)$. A metodologia inicial pressupunha o preenchimento de questionários enviados para casa. Contudo, dado existir uma forte possibilidade de os mesmos não serem devolvidos, e atendendo a que a maioria dos encarregados de educação possuem habilitações literárias limitadas (a escola está inserida num meio fortemente rural, em que as habilitações literárias dos encarregados de educação são, geralmente, baixas, com um elevado nível de analfabetismo, e não ultrapassando, na generalidade, o quarto ano de escolaridade, o que dificultaria o cabal preenchimento do questionário) e para além de não ficarem esclarecidas as condições em que os questionários seriam (eventualmente) preenchidos, optou-se por solicitar aos encarregados de educação que fizessem o preenchimento do questionário, na presença da investigadora, aquando de uma deslocação à escola. Essa decisão, embora acarretando um menor número de respondentes, trouxe a vantagem de conferir uma maior fiabilidade às respostas.

$\mathrm{O}$ estudo decorreu em duas fases. A primeira fase consistiu na aplicação de um questionário aos subgrupos da comunidade escolar (alunos, professores e encarregados de educação), com os objectivos de investigar as concepções e as crenças dos intervenientes bem como de caracterizar as suas atitudes de consumo relativamente a produtos light. Para a concretização do estudo,

Tabela 1 - Distribuição percentual das respostas dos vários subgrupos sobre Onde ou Com quem ouviram falar dos produtos light $(\%)(\mathrm{N}=150)$

\begin{tabular}{lccc}
\hline $\begin{array}{l}\text { Onde ou com Quem } \\
\text { ouviu falar dos produtos light? }\end{array}$ & $\begin{array}{c}\text { Alunos } \\
\left(\mathrm{n}_{\mathrm{A}}=104\right)\end{array}$ & $\begin{array}{c}\text { Professores } \\
\left(\mathrm{n}_{\mathrm{P}}=26\right)\end{array}$ & $\begin{array}{c}\text { Encarregados de Educação } \\
\left(\mathrm{n}_{\mathrm{E}}=20\right)\end{array}$ \\
\hline Supermercados & 72,1 & 92,3 & 65,0 \\
TV / Rádio & 77,8 & 84,6 & 65,0 \\
Jornais / Revistas & 39,4 & 61,5 & 25,0 \\
Cartazes publicitários & 49,0 & 80,8 & 25,0 \\
Familiares & 33,7 & 42,3 & 20,0 \\
Colegas & 51,9 & 42,3 & 25,0 \\
Professores & 8,7 & - & - \\
Outros. Quais? & 3,9 & - & 5,0 \\
Não responde & 1,0 & - & -
\end{tabular}


Tabela 2 - Informações que os alunos que ouviram falar de produtos light na Escola recordam ter ouvido dos seus professores, ordenadas por categoria, subcategoria e frequência do número de respostas (f), num universo de nove alunos $(\mathrm{N}=9)$.

\begin{tabular}{llll} 
Categoria & Subcategoria & $f$ & Extractos das respostas \\
\hline Respostas que associam os & Como produtos com redução de & 1 & "são produtos que não têm tantas \\
produtos light à sua composição & calorias ou gorduras & calorias ou gorduras que os outros \\
específica & & produtos"(A-52)
\end{tabular}

$\begin{array}{lcl}\begin{array}{l}\text { Como produtos que não contêm } \\ \text { açúcar }\end{array} & 1 & \begin{array}{l}\text { "são produtos que não contêm açúcar" } \\ \text { (A-38) }\end{array} \\ \begin{array}{l}\text { Como produtos que contêm } \\ \text { menos produtos prejudiciais à } \\ \text { saúde }\end{array} & 1 & \begin{array}{l}\text { "são produtos que contêm menos } \\ \text { produtos que fazem mal" (A-72) }\end{array} \\ \begin{array}{l}\text { Como produtos que contêm } \\ \text { substâncias em quantidades que } \\ \text { fazem bem à saúde }\end{array} & 1 & \begin{array}{l}\text { "disseram que são produtos que contêm } \\ \text { as quantidades certas e necessárias quase } \\ \text { sempre para o nosso corpo" (A-103) }\end{array}\end{array}$

\begin{tabular}{llll}
\hline $\begin{array}{l}\text { Respostas que associam os } \\
\text { produtos light aos seus efeitos }\end{array}$ & $\begin{array}{l}\text { Como manutenção da forma } \\
\text { física }\end{array}$ & 3 & $\begin{array}{l}\text { "disseram que são produtos que não } \\
\text { fazem engordar" (A-108) }\end{array}$ \\
\hline $\begin{array}{l}\text { Respostas que associam os } \\
\text { produtos light aos que não são } \\
\text { light }\end{array}$ & - & 2 & "são normais como os outros" (A-110)
\end{tabular}

construiu-se e validou-se um questionário focando quatro vertentes: familiaridade dos inquiridos com o tipo de produto, concepções sobre ele, frequência do consumo e opinião sobre a influência do consumo do produto na saúde do coração. Versões com as necessárias adaptações foram aplicadas aos membros de cada um dos subgrupos.

Na segunda fase e a fim de explicitar as eventuais preocupações inerentes (sob o ponto de vista nutricional, económico, etc.) dos responsáveis da Escola onde decorreu o estudo na gestão diária dos espaços escolares relevantes para o efeito - bares e refeitório - foi realizada uma entrevista ao membro do Conselho Executivo responsável pela gestão desses espaços. O protocolo de entrevista foi organizado de modo a que as questões focassem, fundamentalmente, dois aspectos: caracterização do entrevistado no que respeita à sua experiência como responsável pela gestão do refeitório e dos bares escolares e caracterização dos critérios adoptados na gestão daqueles espaços.

Além disso, os dados obtidos através dos questionários e da entrevista foram complementados com a análise de do- cumentos adicionais compostos por relatórios semanais respeitantes à venda de produtos nos bares da escola em períodos distintos.

Por uma questão de simplificação e funcionalidade de consulta, atribuiu-se a cada membro do subgrupo uma letra, em função da inicial do seu subgrupo. Assim, os alunos são referidos, no decorrer do estudo, por $A-1$ a $A-113$, os professores por $P-1$ a $P$-26, os encarregados de educação por E-1 a E-31 e o membro do Conselho Executivo é identificado por CE-1. Designou-se por $\mathrm{N}$ a dimensão do universo das respostas em cada caso.

\section{Resultados}

\subsection{Familiaridade dos participantes com os produtos light}

A análise das respostas ao questionário permite concluir que a grande maioria dos alunos (92,0\%), a totalidade dos professores e uma maioria considerável dos encarregados de educação $(64,5 \%)$ afirma já ter ouvido falar dos produtos light.
Quando se questionam os membros que responderam afirmativamente sobre onde, ou com quem ouviram falar neste tipo de produtos, verifica-se que esse conhecimento vem, sobretudo, de fora da escola: em particular, da TV e rádio, dos supermercados, dos jornais e revistas e dos cartazes publicitários e que são os colegas, logo seguidos dos familiares, os interlocutores privilegiados na divulgação destes produtos aos elementos dos três subgrupos (Tabela 1).

A percentagem de alunos que assinalaram a opção "Professores" como fonte de divulgação deste tipo de produtos é muito baixa (9 alunos, ou seja, 8,7\% dos alunos). Analisando a Tabela 2, verificase que as respostas dos nove alunos acerca do que os professores thes disseram sobre tais produtos fazem referência, sobretudo, à especificidade da composição dos produtos light (quatro referências), aos seus efeitos na forma física dos seus consumidores (três respostas) e à inexistência de quaisquer diferenças entre este tipo de produtos e os restantes (duas respostas).

A análise dos valores e destas respostas permite concluir que, segundo os alunos, os produtos light não são um tema 


\begin{tabular}{|c|c|c|c|c|c|c|}
\hline \multirow[t]{2}{*}{ Categorias de resposta } & \multicolumn{2}{|c|}{$\begin{array}{l}\text { Alunos } \\
(n=104)\end{array}$} & \multicolumn{2}{|c|}{$\begin{array}{l}\text { Professores } \\
\quad(n=26)\end{array}$} & \multicolumn{2}{|c|}{$\begin{array}{l}\text { Encarregados de educação } \\
\qquad(n=20)\end{array}$} \\
\hline & $f$ & $\%$ & $f$ & $\%$ & $f$ & $\%$ \\
\hline Cientificamente aceite & - & - & - & - & - & - \\
\hline Incompleta & 52 & 50,0 & 20 & 76,9 & 19 & 95,0 \\
\hline Com concepções alternativas & 2 & 1,9 & - & - & - & - \\
\hline Outras & 36 & 34,6 & 4 & 15,4 & - & - \\
\hline Não responde & 14 & 13,5 & 2 & 7,7 & 1 & 5,0 \\
\hline
\end{tabular}

abordado com regularidade pelos docentes ao longo do percurso escolar dos alunos e que os poucos alunos que ouviram os professores falar deles não foram capazes de apresentar uma ideia cientificamente aceite e adequada sobre este tipo de produtos.

\subsection{Concepções sobre o conceito de produto light}

Quando inquiridos sobre o que são, em sua opinião, os produtos light, verifica-se que nenhum dos membros dos três subgrupos apresenta uma definição cientificamente aceite, sendo metade das respostas apresentadas pelos alunos, três quartos das apresentadas pelos professores e a quase totalidade das apresentadas pelos encarregados de educação incluídas na categoria das incompletas (Tabela 3).

A análise das respostas classificadas como incompletas permite verificar que estes produtos são associados pelos subgrupos com a sua composição específica (25,9\% das respostas dos alunos, $61,5 \%$ dos professores e $50,0 \%$ dos encarregados de educação) e pelos efeitos que produzem no corpo humano (24,1\% dos alunos, $15,4 \%$ dos professores e $45,0 \%$ dos encarregados de educação). Em relação à composição desses produtos, os três subgrupos associam os produtos light a uma redução do teor calórico (12,5\% dos alunos, $34,6 \%$ dos professores e $35,0 \%$ dos encarregados de educação) e a uma redução no teor dos açúcares (11,5\% dos alunos, 26,9\% dos professores e 15,0\% dos encarregados de educação). Embora este tipo de produtos signifique, efectivamente, uma redução nos teores de hidratos de carbono ou calorias, verificase que nenhum dos sujeitos dos diferentes subgrupos associou os produtos light a uma, também possível, redução nos teores de gorduras, proteínas ou sódio, etc. (Pereira, 2000), identificando apenas duas características dos produtos (valor calórico e conteúdo em hidratos de carbono reduzidos) como associadas à designação light.

\subsection{Hábitos de consumo de produtos light}

A análise dos padrões de consumo dos diferentes subgrupos relativamente a alguns produtos light (margarina, iogurtes, refrigerantes e sumos) permite comprovar que estes não fazem parte dos hábitos alimentares dos três subgrupos, sendo elevadas as frequências de consumo dos elementos que afirmam que nunca ou quase nunca consomem margarina ( $85 \%$ dos alunos, $92,2 \%$ dos professores e $80,6 \%$ dos encarregados de educação), iogurtes (63,7\% dos alunos, $61,6 \%$ dos professores e $61,3 \%$ dos encarregados de educação) e bebidas light (cerca de 40\% dos alunos, 88,3 dos professores para os refrigerantes e $77,0 \%$ para os sumos e $74,2 \%$ dos encarregados de educação para os refrigerantes e $51,5 \%$ no caso dos sumos).

Note-se que o consumo reduzido de produtos light por parte dos subgrupos de alunos e professores poderá estar relacionado com o facto de não haver qualquer produto deste tipo à venda nos bares, tal como referiu no decorrer da entrevista a responsável pela gestão daqueles espaços escolares. Embora se afirme uma não consumidora deste tipo de produtos, reitera que a inexistência destes produtos na escola não é devida às suas opções pessoais, mas antes se deve sobretudo à falta de solicitação dos utentes e ao seu desconhecimento da eventual procura desse tipo de produtos. Definindo-os incompletamente como produtos em que há uma redução de hidratos de carbono - "são produtos em que há uma diminuição de açúcares” -, esta responsável considera a hipótese de os colocar à venda no bar se tal for solicitado pela comunidade escolar.

\subsection{Efeitos do consumo de produtos light na saúde}

Os subgrupos divergem quando associam os produtos light aos efeitos que estes produtos poderão ter sobre a saúde: enquanto um conjunto considerável de encarregados de educação $(40,0 \%)$ e de alunos (18,3\%) associa os produtos light à manutenção da forma física e a um (possível) emagrecimento, os professores $(11,5 \%)$ associam o consumo deste tipo de produtos a uma alimentação mais saudável. Verifica-se, assim, que há uma preocupação do subgrupo dos professores com a saúde e a convicção por parte destes de que os produtos light podem ajudar a melhorar a alimentação, proporcionando, tal como mostra Pereira (2000), um estilo de vida mais saudável, enquanto os subgrupos dos alunos e encarregados de educação associam o consumo deste tipo de produtos a indivíduos que precisam ou querem manter a forma física, numa perspectiva de culto do corpo. No entanto, e como já referimos, o consumo de produtos light só propiciará diminuição de peso, se for consumido nas mesmas quantidades de um produto convencional (Nan, 1999). 
Tabela 4 - Distribuição percentual por subgrupo relativamente às respostas respostas obtidas sobre a relação entre o consumo de alguns produtos light e a saúde do coração ( $\mathrm{N}=170)$.

\begin{tabular}{|c|c|c|c|c|c|c|c|c|c|c|c|c|}
\hline \multirow[t]{3}{*}{ Efeitos } & \multicolumn{12}{|c|}{ Produtos } \\
\hline & \multicolumn{3}{|c|}{ Margarina light } & \multicolumn{3}{|c|}{ logurtes light } & \multicolumn{3}{|c|}{ Refrigerantes light } & \multicolumn{3}{|c|}{ Sumos light } \\
\hline & A & $P$ & E & A & $\mathrm{P}$ & $\mathrm{E}$ & A & $P$ & E & A & $P$ & E \\
\hline \multicolumn{13}{|l|}{$\begin{array}{l}\text { Faz bem ao coração o consumo: } \\
\text { ocasional de uma pequena quantidade, }\end{array}$} \\
\hline regular mas moderado do produto & 9,7 & 19,2 & 19,4 & 14,2 & 23,0 & 9,7 & 7,1 & 7,7 & 3,2 & 11,5 & 15,4 & 9,7 \\
\hline regular ainda que exagerado do produto & 1,8 & - & 3,2 & 9,7 & - & 12,9 & 1,8 & - & 3,2 & 12,4 & - & 3,2 \\
\hline \multicolumn{13}{|l|}{ Faz mal ao coração o consumo: } \\
\hline de qualquer quantidade de produto & 7,1 & 11,5 & - & 0,9 & - & - & 8,0 & 3,8 & 3,2 & 4,4 & - & - \\
\hline regular embora moderado do produto & 3,5 & - & - & 0,9 & - & - & 8,8 & - & - & 6,2 & 3,8 & 3,2 \\
\hline exagerado do produto & 6,2 & 7,7 & 3,2 & - & - & - & 3,5 & 15,4 & 3,2 & 7,1 & 7,7 & 3,2 \\
\hline $\begin{array}{l}\text { Não tenho conhecimentos dos efeitos do } \\
\text { consumo do produto no coração }\end{array}$ & 18,6 & 30,8 & 32,3 & 15,9 & 38,5 & 35,5 & 13,3 & 46,2 & 35,5 & 18,6 & 42,4 & 35,5 \\
\hline Não responde & 40,7 & 23,1 & 38,7 & 42,5 & 30,8 & 32,2 & 51,3 & 23,1 & 45,2 & 31,8 & 26,9 & 38,7 \\
\hline
\end{tabular}

Nota: $\mathrm{A}=$ alunos $; \mathrm{P}=$ professores $; \mathrm{E}=$ encarregados de educação

\subsubsection{Efeitos do consumo de produtos light e saúde do coração}

Em relação às consequências que o consumo de alguns produtos light pode trazer para o funcionamento do coração de pessoas saudáveis (Tabela 4), verifica-se que a maioria dos elementos dos diferentes subgrupos considera que o consumo ocasional ou mesmo moderado de margarina light é benéfico para a saúde do coração. Da mesma forma, a maioria dos sujeitos de qualquer um dos subgrupos afirma que o consumo de qualquer quantidade de iogurtes light traz benefícios para o coração.

No que toca às bebidas light, as opiniões dos três subgrupos divergem: em relação aos sumos light, as opiniões são concordantes relativamente aos benefícios que o consumo destes produtos pode trazer para o funcionamento do coração (mesmo que esse consumo seja exagerado); contudo, em relação aos refrigerantes light, enquanto a maioria dos alunos e dos professores considera que o consumo regular ou exagerado destes produtos poderá ser maléfico para o coração, os professores afirmam que o consumo ocasional de pequenas quantidades de refrigerantes light terá efeitos benéficos no coração.
Note-se, no entanto, que qualquer que seja o produto considerado, há uma elevada percentagem de sujeitos que não responde às questões ou que se afirma desconhecedora dos efeitos que o consumo desses produtos pode trazer ao coração.

A comunidade científica parece ainda não ter opinião formada sobre os efeitos do consumo deste tipo de produtos na saúde do coração. Com efeito, não foi realizado até hoje, pelo menos que seja do nosso conhecimento, qualquer estudo que se debruce sobre este aspecto, e que valide ou não, a utilização destes produtos como benfazejos do coração, o que nos impede de ajuizar sobre a adequação e correcção, ou não, do comportamento alimentar dos membros dos subgrupos relativamente a estes produtos.

\section{Conclusões}

O diagnóstico das ofertas alimentares e do consumo dos produtos light e da análise das linhas de política nutricional que regem o funcionamento dos bares e refeitório na escola onde decorreu o estudo, permite concluir que a escola, apesar da ausência de oferta de venda de qualquer tipo de produto light nos bares, dá, genericamente, cumprimento às Recomendações Nutricionais e Alimentares expressas pelo Conselho $\mathrm{Na}$ cional de Alimentação e Nutrição (CNAN, 1997) para a população portuguesa e as recomendações para bufetes emanadas dos serviços centrais do Ministério da Educação (Circular n. ${ }^{\circ}$ 43/94 de 30/11/1994) e é, nesse sentido, uma escola Promotora de Saúde, na verdadeira acepção da palavra, no que respeita à Educação Alimentar. A oferta de venda de produtos light nos bares escolares estará dependente, segundo a responsável, da solicitação da comunidade escolar para tal.

Apesar disso, os resultados obtidos com a população escolar participante no estudo permitem concluir que:

a) nenhum dos membros dos três subgrupos apresenta uma definição cientificamente aceite de produtos light, sendo a maioria das respostas incompletas. As respostas indicam que estes produtos são associados pelos subgrupos com a sua composição específica (nomeadamente, com uma redução nestes produtos do teor calórico e do teor de açúcares) e com os efeitos que produzem no corpo humano, quer ao nível da manutenção da forma física (alunos 
e encarregados de educação), quer ao nível de alimentação mais saudável (professores);

b) os produtos light não fazem parte dos hábitos alimentares dos participantes no estudo, sendo elevadas as percentagens de elementos dos diferentes subgrupos que afirmam que nunca ou quase nunca consomem margarina, iogurtes e bebidas light. Para tal, poderá contribuir a inexistência deste tipo de produtos à venda nos bares da escola;

c) relativamente à opinião dos participantes no estudo sobre a influência que o consumo dos produtos investigados poderá provocar no funcionamento do coração de pessoas saudáveis, verifica-se que a maioria dos elementos dos diferentes subgrupos considera que o consumo de alguns produtos light (margarina, iogurte e sumos) é benéfico para a saúde do coração. No entanto, enquanto a maioria dos alunos e dos professores considera que o consumo regular ou exagerado de refrigerantes light poderá ser maléfico para o coração, os professores afirmam que o consumo ocasional de pequenas quantidades de refrigerantes light terá efeitos benéficos no coração;

d) a grande maioria dos sujeitos participantes no estudo já tinha ouvido falar de produtos light. A origem desse conhecimento é atribuído por uma grande percentagem de indivíduos, à TV e à rádio, aos supermercados, aos jornais e revistas, aos cartazes publicitários e aos colegas e familiares. A percentagem de alunos que refere terem sido os professores os veículos de informação sobre este tipo de produtos é manifestamente reduzida.

Estas conclusões acarretam consequências quer na incorporação dos produtos light na dieta dos participantes quer em termos de implicações para o ensinoaprendizagem da Química, o que permite referenciar várias implicações para a Educação em Química, ao nível dos diferentes intervenientes: alunos, professores e encarregados de educação.
Se o Ensino Básico pretende formar cidadãos mais esclarecidos e críticos relativamente à sua alimentação e, se no final da escolaridade os alunos desconhecem ou não têm atitudes que indiciem comportamentos salutares, tornase necessário que os produtos light passem a integrar o Currículo Nacional do Ensino Básico. Dado que o currículo já prevê a leccionação do tema Alimentação ao longo dos três ciclos, mas que há ausência de quaisquer referências aos produtos light, defende-se a sua divulgação através da integração de uma vertente de educação alimentar, ao nível da sala de aula, na área de Ciências Físicas e Naturais do Ensino Básico e a construção de um projecto de educação alimentar na escola, de modo a que os envolvidos nesse projecto (alunos, professores e encarregados de educação) melhorem a sua capacidade de fazer escolhas alimentares conscientes e críticas. A análise das orientações curriculares da disciplina de Ciências Físicas e Naturais permite que essa abordagem seja feita no âmbito da leccionação do tema organizador Viver melhor na Terra (DEB, 2002).

Por outro lado, o desenvolvimento do tema "Ciência e Tecnologia e qualidade de vida", incluído no tema organizador Viver melhor na Terra, afigura-se também passível de suscitar a abordagem dos produtos light, devido ao carácter transversal do tema e ao facto de ter como linha orientadora o aprofundamento de "aspectos específicos, essenciais para a compreensão e tomada de decisões face a assuntos que preocupam as sociedades, debatendo factores ambientais, económicos e sociais" (DEB, 2001, p. 35).

Para além disso, os resultados obtidos pelo subgrupo dos professores relativamente aos produtos investigados (reduzido número de respostas cientificamente aceites) tornam urgente a sua formação, seja no âmbito dos cursos de formação inicial, seja em cursos de formação contínua, de modo a melhorar aspectos conceptuais e a alterar hábitos de consumo relacionados com os produtos em causa. A adopção da metodologia de formação assente na aprendizagem baseada na resolução de problemas (Boud \& Feletti, 1997) permitiria um tratamento dos assuntos sob novas perspectivas, fazendo sentir aos professores a necessidade de modificar os seus conhecimentos e a prática docente (Pérez, 1991), e poderia depois ser transposta para a sala de aula de modo a promover a mudança de concepções e de hábitos de consumo referente aos produtos light pelos alunos.

\section{Bibliografia}

Boud, D. \& Feletti, G. Changing problembased learning. Introduction to the second edition. In Boud, D. \& Feletti, G. (Eds.). The challenge of Problem-Based Learning. Londres: Kogan Page Limited, (1997), 1-14.

Codeço, R. Química Alimentar - Um estudo sobre as concepções, as crenças e os hábitos de consumo de uma comunidade escolar relativamente a alguns produtos que interferem com o coração. Dissertação de Mestrado (não publicada), Universidade do Minho, (2003).

Conselho Nacional de Alimentação e Nutrição (CNAN). Recomendações para a Educação Alimentar da População Portuguesa. Lisboa: CNAN (1997).

Coucello, T. Educação Alimentar: práticas e discursos dos médicos de clínica geral. Lisboa: Educa-Formação (1997).

DEB (Divisão de Ensino Básico). Currículo nacional do ensino básico. Competências essenciais. Lisboa: Ministério da Educação (2001).

DEB (Divisão de Ensino Básico). Ciências Físicas e Naturais - Orientações curriculares para o $3 .{ }^{\circ}$ ciclo do ensino Básico. Lisboa: Ministério da Educação (2002).

Nan, P. Diet ou Light? O consumidor, 8 (1999) 10-11.

Pereira, D. Light ou Diet? Eis a questão! 0 consumidor, 15 (2000) 24-25.

Pérez, G. Qué hemos de saber y saber hacer los profesores de ciencias?.Enseñanza de las Ciencias, 9 (1), (1991), 69-77.

WHO (World Health Organization) Study Group. Diet, Nutrition and the Prevention of Chronic Diseases. Genebra: WHO (2002). 